\title{
Drawing Gender Equality: A Participatory Action Research Project with Educators in Northern Uganda
}

\author{
Shelley Jones
}

\begin{abstract}
This paper reports upon an arts-based participatory action research project conducted with a cohort of 30 teachers in rural Northwest Uganda during a one-week professional development course. Multimodality (Kress \& Jewitt, 2003; Kress \& van Leeuwen, 2001) was employed as a "domain of inquiry" (Kress, 2011) for social semiotics (meaning-making within a social context) within which the participants both represented gender inequality as well as imagined gender equality. Multimodality recognizes the vast communicative potential of the human body and values multiple materials resources (such as images, sounds, and gestures) as "organized sets of semiotic resources for meaningmaking" (Jewitt, 2008, p. 246). Providing individuals with communicative modes other than just spoken and written language offers opportunities to include voices that are often not heard in formal contexts dominated by particular kinds of language, as well as opportunities to consider topics of inquiry from different perspectives and imagine alternative futures (Kendrick \& Jones, 2008). Findings from this study show how a multimodal approach to communication, using drawing in addition to spoken and written language, established a democratic space of communication. The sharing and building of knowledge between the participants (educators in local contexts) and facilitator (university instructor/researcher) reflected a foundational tenet of engaged scholarship which requires " ... not only communication to public audiences, but also collaboration with communities in the production of knowledge" (Barker, 2004, p. 126).
\end{abstract}

KEYWords Multimodality, gender, education, drawing, Uganda, engaged scholarship

Gender inequality in education remains problematic in Uganda, as well as many other parts of the world, despite initiatives and policies - international as well as national-intended to eradicate the these inequalities. The nature and prevalence of gender discrimination is deeply embedded in cultural constructs around gender that have become normative through their embeddedness in practices, both institutionalized and cultural, over a long period of time.

In North West Uganda, where this study took place, the challenges girls face with respect to equal educational opportunities are more pronounced than in most other parts of the country (Faughnan, 2016; Stoebenau et al., 2015; Uganda Bureau of Statistics (UBOS), 2012).

Educators are tasked with establishing "gender-responsive" and/or "gender-sensitive" learning environments, and yet there is little, if any, consultation with educators about their local contexts and their needs to promote gender equality. In addition, many educators- 
especially in rural areas — are not even aware of the policies intended to guide their practice with respect to cultivating gender equality in schools. Without dialogue between policymakers and policy-mentors, policies will have little chance of being enacted. What is required, therefore, are opportunities for such dialogues to transpire.

However, the policy discourse around gender equality, like most policy discourses, is typically limited to the modality of formal language (spoken or written). It excludes the voices of those who do not operate competently or confidently in this formal modality and who are therefore denied access to official contexts in which decisions are made. And, genderbased experiences differ, based on context, so those creating policies and programs may not fully grasp the realities that teachers must grapple with on the ground. With the intention of sharing and building knowledge between the community and the university, this project was undertaken within the parameters of an engaged scholarship model that emphasizes the "pedagogical value of collaborating with publics instead of providing information to or services for publics" (Barker, 2004, p. 127) through "bidirectional interactions, reciprocity, and mutual respect" (Sandmann, 2008, p. 94). In order to expand the discourse of gender equality beyond the mode of formal language, and include marginalized voices, this study employed multimodality as a "domain of inquiry" (Kress, 2011, p. 242).

This study draws on data gathered during a week-long professional development course that I, along with a Ugandan Professional Development Tutor, facilitated for 30 pre- and primary school educators in North West Uganda. The workshop was concerned with creating gender-responsive learning environments, and the participants conducted explorations into the nature of gender constructs and inequalities through a variety of modes - drawing, theatre, and creative writing - in addition to spoken and written language. This paper is specifically focused on how drawing as a mode contributed to the discourse of gender equality. (Discussion of other modes used have been written about it another paper, see: Jones, 2018.)

\section{Multimodality as a "domain of inquiry" for engaged scholarship}

This study draws upon multimodality as a domain of inquiry within which social semiotics (meaning-making) can be explored and understood (Kress, 2011). Social semiotics involves sign-makers (individuals who initiate a communicative act) who chose from a selection of materials/ materiality_or modes (such as images, gestures, sounds, colours, framing)— to produce signs (representations of meaning). Signs are created in response to prompts, such as questions or messages to be answered or communicated, and the social semiotic process begins with individuals' experiences, knowledges, and understandings of the world (Cope \& Kalantzis, 2000; Jewitt, 2008) and is then acted upon through practices that engage with resources/modes to create signs, which are then taken up and interpreted by those who interact with the sign.

Within formal institutions of power — such as government, the judiciary, and educationlanguage (spoken and written) has long dominated as the preferred and privileged communicative mode. Furthermore, particular kinds/aspects of language (for example, accent, dialect, and lexicon) are and have been valued more than others (Norton, 2013). Language, and these 
specific, hegemonic forms of language have constituted a modal 'social capital' (Bourdieu \& Wacquant, 1992) for those who possess and are adept at expressing themselves in this mode. Individuals who speak/write the dominant language of power and the specialized languages (of, for example, politics, finance, trade) within that language are entitled to power, privilege and opportunities that are not available to those who are not proficient in this mode (Foucault, 1980; Norton, 2013; Tozer, 2000). Decisions made within this monomodal, prioritized, realm of dominant language often do not involve, or consider the voices of those marginalized from this realm—such as women and girls in highly patriarchal societies_but who are nonetheless deeply impacted by the decisions made.

Multimodality, on the other hand, challenges the primacy of monomodality by considering language as just one of multiple, legitimate communicative modes (Kress, 2011; Kress \& Jewitt, 2003). Within the domain of multimodality, sign-makers have a choice of modes through which they can convey their ideas, and thus the hierarchical precedence of language is subverted. The use of different modes produces signs which although perhaps presenting the same knowledge, present it from a different epistemological orientation: 'knowledge' appears differently in different modes" (Kress, 2011, p. 242). Modes can be complementary and interact with each other, which can infuse the semiotic process with additional layers of meaning at both the creation and interpretive stages: "any communicative event involves simultaneous modes whereby meaning is communicated in different ways through images, gestures, and speech" (Kendrick, Jones, Mutonyi, \& Norton, 2006, p. 97).

The creation and interpretation of signs is a social act that happens within social contexts that are infused with culture, history, and knowledge that also contribute to the significance and communicative potential of the signs (Kress, 2011). Context is, therefore, also an integral aspect of social semiosis. The shared space and time within which signs are made and interpreted contributes to the depth and complexity of meaning-making and lends itself to a particular understanding of the discourse with which they are engaged:

Which discourses interpreters or users may bring to bear on a semiotic product of event has everything to do... with their place in the social and cultural world, and also with the content. The degree to which intention and interpretation will match depends on context (Kress \& van Leeuwen, 2001, p. 8).

When different modes are recognized as having equal semiotic potential and the communicative context of space and time is intentionally inclusive, voices that are not typically heard within the dominant discourse through the dominant mode are able to contribute to discourses through modes with which they are adept and feel comfortable. Kress (2011) states that "semiotic affordances of modes have a large epistemological effect" (p. 249); the inclusion of often unheard voices through these varied modes enables the discourse to be understood from new and unfamiliar perspectives. Multimodality thus has the potential to provide a means by which to transform and democratize communicative social capital by extending modes of inquiry and expression far beyond the traditional, hegemonic, limiting, and often exclusionary 
modes (such as formal speech and written text) in a deliberate attempt to include and value the contributions of those who are often not heard (often women).

Policies and initiatives that are intended to bring about transformative social change through implementation by individuals on the ground require their input and commitment. However, these individuals, who are enmeshed in local contexts, are often not well-versed in the hegemonic power of formal, institutional language and do not have easy access to power structures that prepare the directives they are meant to follow. Their voices are often marginalized, overlooked, unsolicited, or ignored. Therefore, in the spirit of engaged scholarship, a multimodal approach was taken for this study so that the discourse of gender equality could be explored in poignant, authentic, unconventional ways and establish a "twoway street of interactions or partnerships between the academy [and other institutions of power] and the outside world" (Spanier, 1997, p. 8). Semiotic engagement with multiple modes offered participants communicative potential and opportunities that would not be available in a normative, formal professional development context where language was privileged over all other modes.

Through drawing, drama, and creative writing, in addition to formal language, the participants explored complex constructions, enactments, and experiences of gender relationships and gendered experiences related to school contexts in rural Northwest Uganda. Although each mode offered rich data with respect to insights into the complex nature and multiple manifestations of gender inequality, this paper focuses on the drawings created by the participants and the layers of meaning they embody. These drawings became semiotic points of engagement that stimulated perceptions and sensations in others (Pink, 2011; Roswell \& Pahl, 2007), serving semiotic points of reference for not only the "what is" but the "what might be":

Providing opportunities...to explore and consider their worlds through alternative modes of communication and representation has immense potential as a pedagogical approach to cultivate dialogue about the nature of gender inequities, and serve as a catalyst for the positing of imagined communities where those inequities might not exist (Kendrick \& Jones, 2008, p. 397).

\section{Background to the Study}

In Uganda, gender equality with respect to education remains problematic (Blackden, 2004; Bantebya, Muhanguzi, \& Watson, 2014; MoGLSD, 2007; Ministry of Education and Sports, Uganda [MoES], 2016; UNDP, 2015). Despite the significant quantitative gains that have been made with in terms of girls' access to and enrollment in school, where full, or near gender parity at both the primary and secondary school levels has been achieved (Kwesiga, 2003; MoES, 2013; UNESCO, 2017) ${ }^{1}$, many cultural, social, economic inequalities persist (MoES, 2013, 2016). These include: unfair burden of domestic duties (Jones, 2008, 2011; MoES, 2013;

\footnotetext{
${ }^{1}$ It must be noted, however, that although net and gross enrollment rates for both females and males is relatively high at the primary school level, primary completion rates are low, as is secondary school attendance.
} 
Stoebenau et al., 2015); risk of sexual assault/harassment commuting to/from school (Geiger, 2002; Jones, 2008; 2011; MoES, 2013, 2016); and parents' prioritization of boys' education over girls' (Jones, 2008; 2011; MoES, 2013, Stoebenau et al., 2015).

Within the school itself, there are numerous environmental, pedagogical, and social factors that mitigate against girls' equal participation and treatment. Didactic pedagogical approaches centered around compliant behaviour, closed questions, exam-based teaching, tend to favour boys (to whom most of the teachers' attention is directed, and of whom most questions are directed) and marginalize or exclude girls who are expected to be submissive and take a back seat to the boys (Kakuru 2006; Mirembe \& Davies, 2001; Mlama, Dioum, Makoye, Murage, Wagah, \& Washika, 2005). Girls are often perceived by their teachers as not possessing the same academic capabilities (Geiger 2002; Jones, 2008; Mirembe \& Davies, 2001).

Table 1. 2013-2016 education statistics, Uganda

\begin{tabular}{|l|l|l|l|l|l|l|l|}
\hline & $\begin{array}{l}\text { Pre-primary } \\
- \text { gross } \\
\text { enrollment } \\
(\%) \\
(2016)\end{array}$ & $\begin{array}{l}\text { Primary } \\
\text { net } \\
\text { enrollment } \\
(\%) \\
(2016)\end{array}$ & $\begin{array}{l}\text { Primary } \\
\text { gross } \\
\text { attendance } \\
(\%) \\
(2013)\end{array}$ & $\begin{array}{l}\text { Primary } \\
\text { net } \\
\text { attendance } \\
(\%) \\
(2013)\end{array}$ & $\begin{array}{l}\text { Primary } \\
\text { school }- \\
\text { survival } \\
\text { rate to last } \\
\text { primary } \\
\text { grade }(\%) \\
(2014)\end{array}$ & $\begin{array}{l}\text { Primary to } \\
\text { secondary } \\
\text { transition } \\
\text { rate }(2014)\end{array}$ & $\begin{array}{l}\text { Secondary } \\
- \text { gross } \\
\text { attendance } \\
(\%) \\
(2015)\end{array}$ \\
\hline Girls & 11.84 & -- & 110.91 & 95.11 & 21.63 & 52.82 & 22.13 \\
\hline Boys & 11.63 & -- & 108.87 & 92.21 & 21.09 & 54.98 & 24.34 \\
\hline
\end{tabular}

Source: UNESCO (2017)

In addition, resource materials are often replete with depictions of gender stereotypes which serve to reinforce negative and/or limiting conceptions of girls' abilities and opportunities (Jones, 2015; Mlama et al., 2005). Also, it is not unusual for girls to be required to assume extra domestic duties at school (e.g., serving tea to the teachers, washing dishes, cleaning the compound), which are not expected of boys, which negatively reinforces stereotypes and demeans girls' images as equal and respected participants in the learning environment (Jones, 2008). Furthermore, sexual harassment, assault, and exploitation by both male students as well as male teachers in the school context, as well as by men in the surrounding area during the girls' commute to and from school are prevalent (Jones, 2008; 2011; Mirembe \& Davies, 2001; Mlama et al, 2005; MoES, 2013, 2015). All of these factors hinder girls' equal participation in school as well as contribute to their lack of confidence in their own abilities (Stoebenau et al., 2015). The extent to which girls are impacted by these (and other) factors vary throughout the country, and are largely reflective of regional and socioeconomic disparities (Lawson, 2003; MoES, 2013, 2016; UBOS, 2017). The West Nile Sub-Region of Uganda, where this study took place, has the highest gender gap in enrollment in the country, with only six girls in school for every 10 boys (UBOS, 2015). In the West Nile region of Uganda, girls' attendance and retention in school are particularly problematic (Faughnan, 2016; MoES, 2016; Stoebenau et 
al., 2015; UBOS, 2012).

National planning documents, such as Uganda Vision 2040 (Government of Uganda, 2007), and policies and documents such as the National Strategy for Girls' Education (NSGE) (MoES, 2013), the Gender in Education Sector Policy (MoES, 2016), and the Uganda Gender Policy (Government of Uganda [GOU], 2007), as well as external organizations' initiatives such as UNDP Uganda's Gender Equality Strategy 2014-2017 (UNDP, n.d.) all recognize the urgent need to work towards achieving gender equality. However, there remains a large gap between policies and strategies and their effective implementation on the ground. In fact, teachers are very often utterly unaware of the existence of these documents, let alone provided with the professional development required to operationalize them. Thus, there is need for an engaged scholarship approach to working with local educators to not only ensure they are familiar with relevant policies and initiatives, but to ensure that their experiences, knowledge, and voices inform these directives.

\section{The Study}

\section{Participants and location}

This study involved 30 pre-primary and primary school educators from the West Nile Sub-Region of Northern Uganda. The participants attended two, one-week professional development courses (October, 2014 and March, 2015) which was a part of the Strengthening Education Systems in East Africa (SESEA) initiative (funded by the Department of Foreign Affairs and Trade Department of Canada, and implemented by the Aga Khan Development Foundation). Data collected for this paper was from the first workshop (October, 2014). With support from a Ugandan Professional Development Tutor (teaching assistant), I developed and facilitated the courses which focused on promoting and establishing gender-responsive schools. The following chart indicates the sex and designations of the participants.

Table 2. Sex and designation of study participants

\begin{tabular}{|l|l|l|l|}
\hline Designation & Female & Male & Total \\
\hline Head teachers & 1 & 4 & 5 \\
\hline Pre-primary Teachers & 9 & 6 & 15 \\
\hline Primary Teachers & 10 & 5 & 15 \\
\hline
\end{tabular}

The course was held in a Teachers' College in a rural setting. Participants who lived and worked at a distance from the college resided in the college dormitories. All accommodation and meals (or daily travel costs for those who lived nearby) were provided.

\section{Feminist, participatory action research framework}

As the focus of the study was finding ways to work towards promoting and sustaining gender equality in educational contexts, I employed a feminist, participatory action research (FPAR) methodology for this study. The FPAR methodology positions participants as the experts of their contexts, and the researcher as a facilitator who defers to their expertise (Lather, 
2004). As a white Canadian female, I positioned myself as an etic facilitator: I could offer information, strategies, and observations, but it was the participants' knowledge and insights that constituted the material we worked with.

The FPAR approach intentionally challenges and disrupts normative, patriarchal, hegemonic structures that hinder gender equality by ensuring that all voices are included and valued, with particular attention and support provided to those whose voices have traditionally been excluded to overtly acknowledge the importance of their contributions. Active democratization of voice and participation is essential to create a community of trust and support where deeply complex and highly sensitive issues - such as those relating to gender discrimination and abuse_can be meaningfully explored (Maguire, 1996). As a facilitator, I strove to accomplish this through the activities, and established, agreed-upon codes of interpersonal conduct that we engaged with throughout the course.

Admittedly, the participants were not involved in the research design and so their input was not sought to determine which research methods they would think to be most effective and meaningful, given the topic; this is acknowledged as a shortcoming of the participatory nature of the study. However, drawing is considered conducive to feminist research methodology:

...the physical act of creation and the bodily engagement with one's environment fosters, according to Gauntlett (2007), a different type of cognitive process, which transcends the domain of purely cerebral thought. In view of these features, RattineFlaherty and Singhal (2007) convincingly argue that visual participatory research strategies are an inherently feminist approach, due to their valuing of subjective, emotional, and co-constructed ways of knowing. (Literat, 2013, p. 88)

The participants assumed the role of researchers as they engaged in the discourse around gender, and investigated and deconstructed assumptions and constructs associated with this discourse.

\section{Methods}

A mixed-methods approach was employed for data collection. The participants completed preand post-course questionnaires for the course, as well as end-of-course reflective summaries on the activities undertaken during the course. Throughout the course, the participants engaged in a number of multimodal activities (including drawing, drama, and creative writing) that were recorded - through photographs and videorecording — as data; this paper, however, focuses on the drawings produced by the participants. In addition, discussion and observations during the activity sessions were recorded by notes taken by me.

\section{Analysis}

I drew upon a constructivist grounded theory (Charmaz, 2006, 2008) approach to analysis, in two stages. During the first stage, I worked inductively and iteratively from the data collected at the beginning of the course where the discourse of gender (in)equality was considered. I 
triangulated and coded drawings, notes taken from discussions and participant observation, brainstorming charts, questionnaire responses, drawings, and video footage according to key signs/concepts (such as "beating", "ignored", "fetching water") that emerged. I then grouped the codes in categories to identify salient themes (such as "sexual abuse", "physical abuse", and "neglect"). I discussed these themes with the participants to ensure their validity. The analysis process was iterative (Grbich, 2013) and collaborative.

The second stage of analysis involved a deeper examination of data produced as representative of social semiotics within the domain of multimodality. Data considered for the purposes of this paper are the drawings produced by the participants. I studied the drawings and coded elements that might convey particular, shared meaning and sub-text to the participants beyond the interpretation of the image at surface level for someone unfamiliar with the context. For example, objects represented in the drawings - such as jerry cans, machetes, school uniforms, and firewood-evoke embodied, sensory associations for those, such as the participants, who have experience with these objects, but would not have the same impact or associations for those who are not. I grouped these codes into themes-physical and sexual abuse, neglect and exclusion, exploitation of girls' labour, gender roles and stereotypes, and disruption of traditional roles and responsibilities - which then enabled me to begin to understand the multiple meanings and depths of meaning each drawing represented. It was through this second level of analysis that findings related to multimodality as a domain of inquiry emerged.

\section{Findings and Discussion \\ Identifying Gender(ed) Discourses}

Limitations of formal, spoken language as mode. The study began with discussions on discourse(s) on gender in the local context. Key points made from initial discussions, were recorded on chart paper. We then discussed these points in relationship to gender-based challenges that negatively impacted girls' educational opportunities. Again, observations were recorded on chart paper:

- Unfairly onerous domestic chores for girls that prevented their attendance at school;

- High drop out rates for girls;

- Boys privileged over girls - generally, and with respect to educational opportunities in families;

- Girls' low self-esteem; girls' late enrollment in school; prescriptive, rigid gender roles and expectations in society that girls were expected to adhere to;

- Gender stereotyping of subjects, directing girls away from, for example, math and science;

- Pedagogical approaches that favoured boys;

- Fewer girls in leadership positions; teachers' negative attitudes about girls' abilities;

- A lack of access to sanitary materials during menstruation;

- Early marriage and/or early pregnancy that led to girls' drop out; and

- Sexual harassment, assault exploitation to/from/at school. 
These issues were generally agreed upon by all participants and concurred with various other studies and reports concerned with gender inequality in education.

Although I had actively encouraged everyone to share their thoughts, the men dominated the discussions, and many of the female participants-particularly those who held the lesser respected positions such as pre- and early primary schoolteachers, were reticent to say anything at all. Clearly there existed a fundamental power differential based on gender alone, but that seemed to be exacerbated by the mode of spoken language in a formal/professional context. In addition, many of the female participants had had fewer years of education and were less fluent in English (the dominant, official language in formal contexts) and so at times found it challenging to articulate their ideas through the mode of (spoken, formal, English) language. Thus, within a very short time (less than an hour from the time the course began) gender(ed) and status-related power dynamics between the participants had been established: the men dominated discussions and many of the younger women, or women in lower positions were silent. However, it was the voices of the women in the course who felt intimidated or reticent to contribute that were precisely the voices that needed to be heard.

Drawing as an alternate mode of inquiry. In order to extend communication beyond the limitations of this mode of formal, spoken, English language, I asked the participants to engage with the mode of drawing to explore representations of gender inequality. This suggestion met with much laughter and some nervous comments about lack of artistic abilities. I assured the participants that artistic ability was not being evaluated, simply that drawings might reveal some interesting details and nuances that might otherwise not come through in verbal exchanges. The room became quiet - except for murmured exchanges and some laughter-as the participants focused on creating their drawings representing an aspect of gender inequality that they wished to share. All participants taped their drawings to the wall. We then took a gallery walk and closely viewed each of the drawings.

The creators of the drawings were not identified unless they chose to be. Some of the participants included captions (some short, some quite detailed). Most of the themes, discussed below, that had emerged through the opening session were also represented in the drawings, but the drawings embodied messages, knowledge, and implications beyond what had been conveyed in the verbal discussion and the written text of the list of issues (Figure 1) related to gender discrimination.

We discussed each of the drawings, and rich and layered meanings represented in these drawings became more evident as the people, objects, places, situations, and actions depicted were interpreted. As an outsider, I would have not understood many implications visually represented. Rose (2016) argues that it is important to understand "visual images as embedded in the social world and only comprehensible when that embedding is taken into account (p. xxii), and I acknowledge the critical necessity of shared analysis with the participants to interpret (or rather relay their interpretations) of these visual representations with reasonable accuracy. Below are the major themes that arose from these drawings: physical abuse, sexual violence, neglect and exclusion, and exploitation of girls' labour. 


\section{Physical abuse}

Figure 1 depicts a theme that was common to many of the drawings — a boy beating a girl.

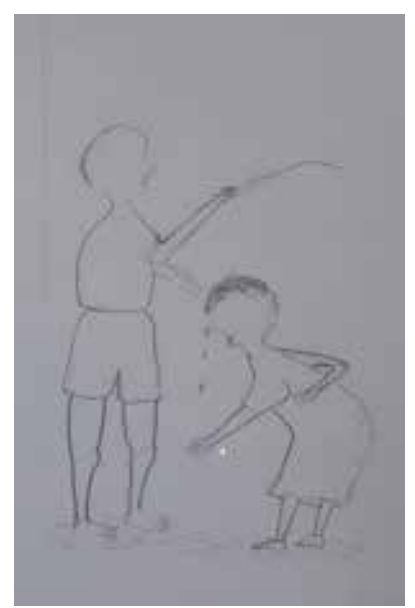

Figure 1. Boy beating girl with stick

In Figure 1, the boy is clearly in the position of power, standing tall, right arm raised, hand holding a stick with which is beating the girl. The girl is bent over, facing the ground with her right arm twisted behind her back. The girl's tears are visible, falling to the ground. The caption, using writing as a complementary mode, reads, "A big boy caining [sic] a girl for performing better than him in class." This picture represents the intersectionality of numerous, prevalent discourses around gender: the power males assume they have over females; the fear males have over females who rival their superior status become successful (i.e., "performing better"); the commonplace practice of physical violence against girls and women. In addition, the action of males beating females with sticks or other objects is a form of violence that was a shared knowledge/understanding of violence for the participants, as they had all witnessed it (and perhaps themselves been victims of it) in their schools and communities. Interestingly, the picture seemed to prompt speculation beyond the content of the drawing itself from the creator about the motivation behind the boy assaulting the girl — that is, he was jealous of her performance. Figure 2 shows a boy assaulting the girl.

This drawing, too, was accompanied by a written description of the situation:

Boys tend to challenge girls, they feel stronger than the girls, fluent in spoken English (language). In the picture, the boy is challenging the girl thinking that she cannot speak good English. He want to know whether she can defend herself. Boys do not want girls to pass ahead of them in examinations and other activities.

Figure 2 conveys similar messages as Figure 1 with respect to boys' fear of girls' academic success. However, as discussed by the participants, the reference to speaking English is an important aspect of the reflective description. Fluency in English is representative of power,

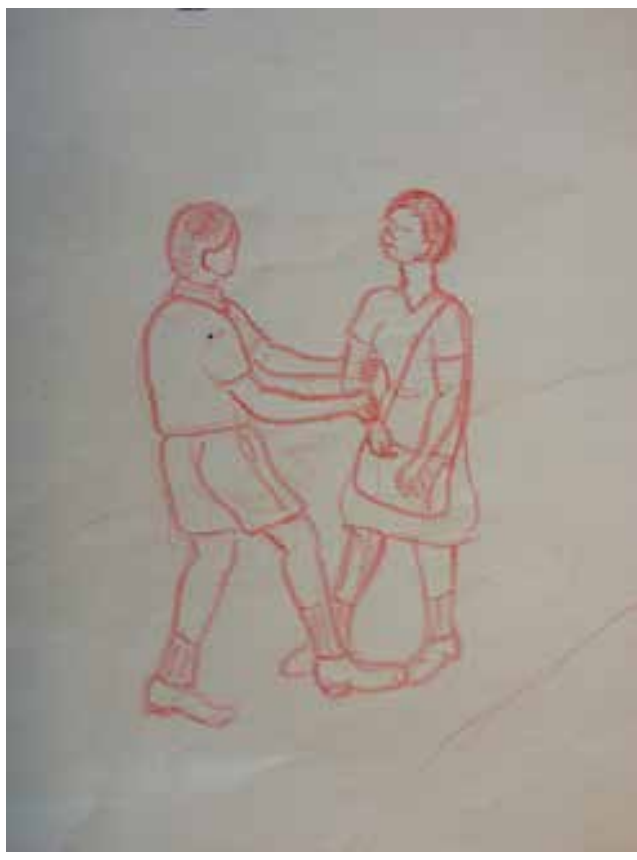

Figure 2. A boy assaulting a girl 
success, and opportunities for social, political, and economic advancement and the boys are protective of their perceived advanced standing/abilities in this area. The drawing itself does not immediately communicate this message to the viewer, but it is the written engagement with the drawing - the result of intersections of two different modes - that has drawn this reflection from the creator. And, it was the participants' understanding of the significance of fluency in English that provided a further layer of meaning and expanded the semiotic implications beyond the act of physical violence portrayed to dimensions of power (associated with language, education, as well as gender) in society.

Discussions around these two drawings revealed some interesting underlying sociocultural assumptions-that boys are men generally consider themselves to be more "powerful" (stronger, more intelligent, more capable) than girls and women and this often lends itself to a position of male dominance, whether in the family home, in the classroom, or in the workplace. When girls or women are seen to be challenging their position through academic or professional success or advancement, men often feel threatened and violence can ensue. The participants discussed the importance of enabling girls and boys to both be given opportunities to succeed and to learn to support each other's successes. In one of the reflective pieces written at the end of the course, a participant commented, "Both boys and girls are to be considered equal especially in answering questions, playing roles, discussions, leadership, and other activities at school."

\section{Sexual violence}

Sexual violence is another theme that arose in the drawings. Figure 3 shows a boy sexually assaulting a girl. The drawing shows the girl and boy both in their school uniforms, suggesting that this is an occurrence at school. The boy is leaning towards the girl and, almost nonchalantly, lifting the girl's skirt. The girl is leaning away from the boy slightly, but seems to demonstrate a submissive, or resigned, acceptance of abuse/assault.

Figure 4, below, shows girls and boys seated separately in the

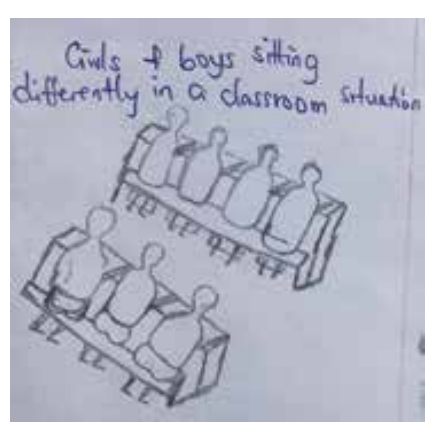

Figure 4. Girls and boys seated separately in classroom classroom.

The accompanying summary of this drawing, however, reveals a message that extends beyond the simple image:

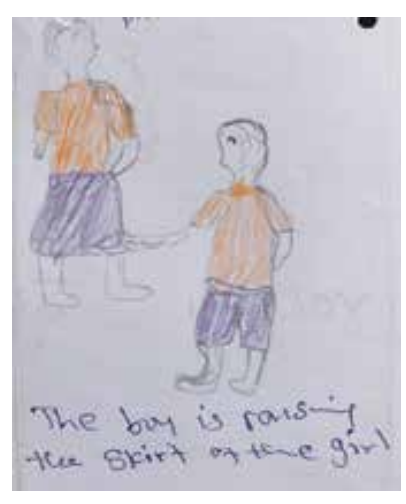

Figure 3. Boy lifting a girl's skirt

The boys and girls do no want to sit together on the same desks because boys disturb the girls by pinching, kicking their legs, knocking their heads even when teacher is teaching and worse when teacher is not in the classroom. Some boys touch the girls in the private sensitive regions like the breast or pubic region. Some boys steal girls belongings like pens, 
sets of books.

The semiotic significance underlying the reasons for the girls and boys sitting separately would likely not be interpreted by a viewer who is not familiar with this context, but the participants easily recognized these reasons from their own experiences.

Figures 3 and 4 inspired a larger discussion around the sexual abuse of girls by both male students and male teachers. The participants shared instances with which they were familiar, as well as various strategies, policies, and procedures for preventing and punishing assaults against girls. Participants discussed strategies that they could employ in their schools to reduce sexual harassment and offer support to girls when needed. In the reflective writing piece at the conclusion of the course, one male participant wrote: "[We need to] reduce drop out rates and [increase] retention of girls in schools [by ending] gender based violence."

\section{Neglect and exclusion}

A number of drawings depicted the many ways that girls' educational opportunities are compromised by neglect and exclusion in the classroom context. The following drawings speak powerfully to the argument that access to schooling is not enough to bring about gender equality in education (Jones, 2008; 2011). Girls are entitled to quality of education and educational experiences and the same (if not more, given the long history of discriminatory practices that have perpetuated their marginalized positions in society) opportunities as boys, such as attention from, and support by teachers, access to resources, leadership positions, freedom to play and rest outside of class time. However, disparities between girls' and boys' experiences at school are starkly depicted in the drawings following.

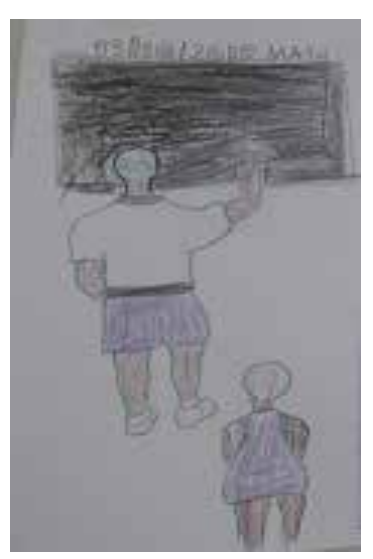

Figure 5. Boy doing math calculations; girl in background

Figure 5 depicts a boy at the blackboard calculating a math problem, while a girl stands behind him and watches.

The girl and the boy are both in their school uniforms, and are both in the same math class, but their experiences are very different. The accompanying summary of the drawing states: "Girls fear math as a result of the societal beliefs that math is too difficult for girls and can only be well done by boys. They get the negative idea from the society." The comparative sizes of the boy (very large) and the girl (about half his size) suggest a significant power differential. Discussion around this drawing evoked observations that boys typically have access to resources that are not available to girls, including access to the attention of the teacher, who- - in this casewill presumably review the boy's calculation.

Figure 6 is another example of the exclusion of girls from equal learning opportunities within the classroom. 


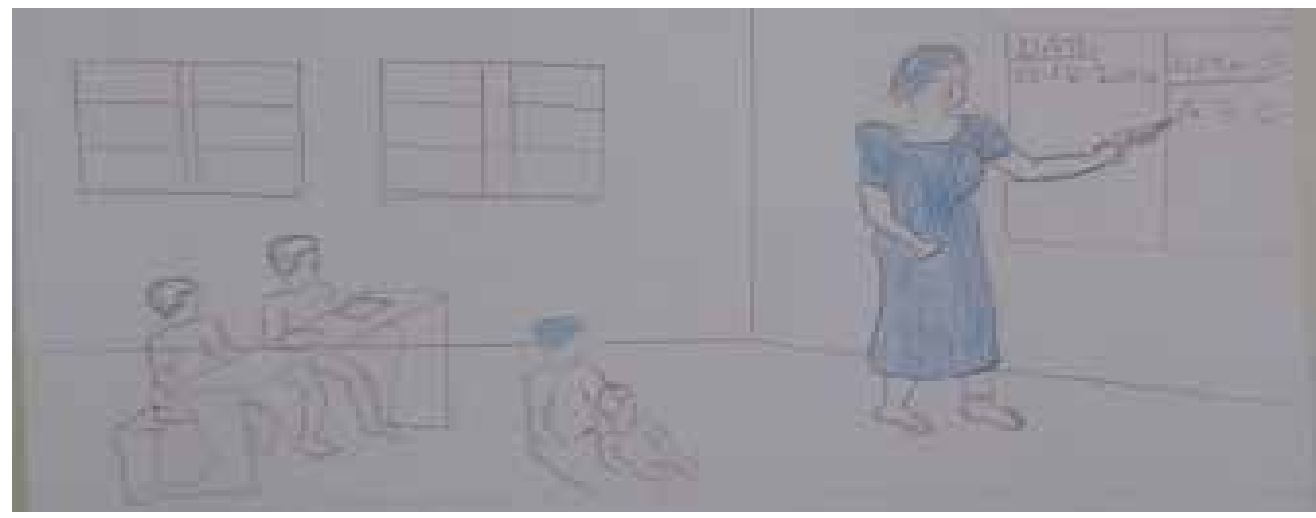

Figure 6. Girl sitting alone on floor in classroom

This drawing depicts a classroom setting where two schoolboys are seated at a desk, with books. The teacher is standing at the chalkboard, giving a lesson. A girl is sitting on the floor, with no book, looking after an infant. The infant is most likely that of the teacher, as it is not uncommon for teachers to bring their young children with them to school and for the female students to be expected to take care of them. Aside from the obvious inequities with respect to access to resources and equal learning opportunities, the representation of the power differentials between the boys and the girl-the boys seated on a higher level on formal classroom benches, and the girl seated on a dirt floor without even a cloth beneath her clothes-is clearly evident.

Figure 7 directly contrasts the attention received by a boy and a girl from their teacher.

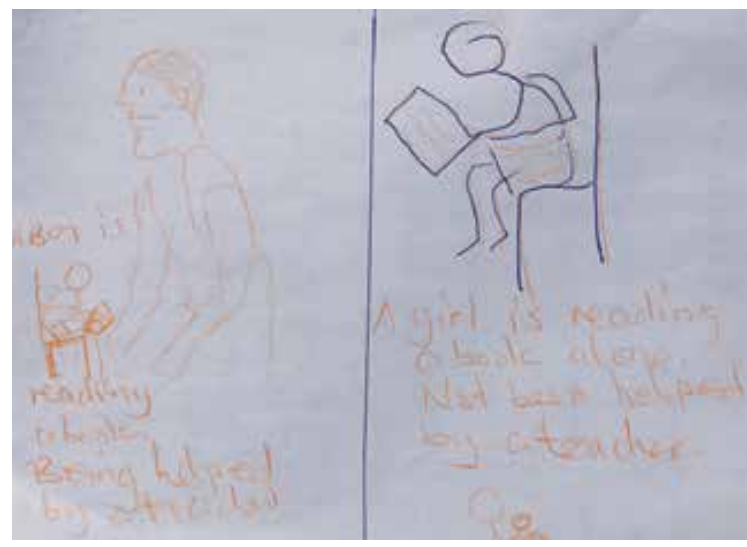

Figure 7. Contrast of attention given by teacher to boy and girl

On the left, a boy is sitting on a chair, reading a book, while the teacher leans towards him, providing him with assistance. The caption reads: "A boy is reading a book being helped by a teacher." On the right, a girl is sitting by herself, with a book, and receiving no attention from the teacher. The caption reads: "A girl is reading a book alone. Not been [sic] helped by a teacher." The participants articulated that this drawing conveys the message that even if girls have access to school, and even if they also have access to the same material resources (book, chair), this does not guarantee that they have equal learning opportunities (e.g., support from their teacher).

Figure 8 shows a girl reading alone, outside the school, communicating the message that she does not have access, or is not included, or does not belong (or feel she belongs) within 
the school.

The creator's full summary of the drawing reads: "Girl reading alone without help by teacher. In some schools teachers tend to help boys in their studies more than girls. Girls were not given opportunities [in] other areas especially leadership, and their rights area abused..."

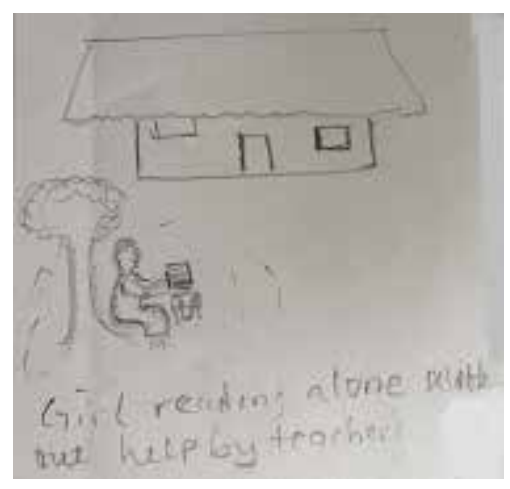

Figure 8. Girl reading alone

These drawings instigated an in-depth discussion about the discrepancies in attention and opportunities received by girls and boys at school, and the participants eagerly shared and proposed a number of strategies to overcome this. Following are some select excerpts from the final reflective writing relating to this topic include: "girl child education [should be] a priority"; "[there needs to be] gender consideration in our schools and classrooms." The complementary nature and integration of the three modes_-drawing, writing, and spoken language — enabled the participants to explore the semiotic depth and richness of the sign from various perspectives and senses.

\section{Exploitation of girls' labour}

Schools require ongoing maintenance as well as provision of services, but because so many schools (particularly those in poor, rural areas) are very poorly resourced, much of this maintenance and service falls upon the students, with an inordinate amount expected from the girls. Figure 9 shows two schoolgirls washing the classroom floor.

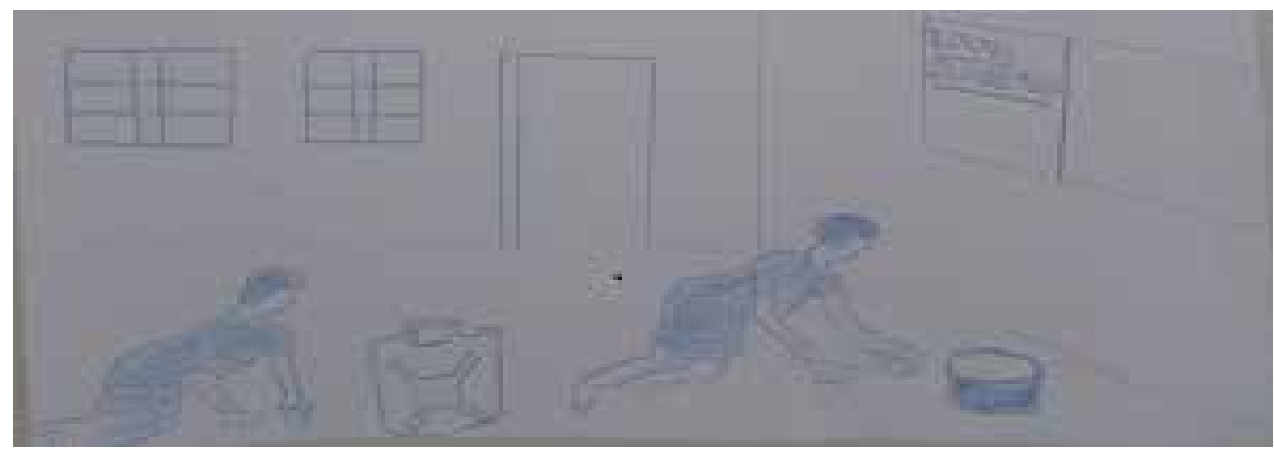

Figure 9. Schoolgirls washing classroom floor

The girls are sprawled on the ground, with a jerry can containing water (which they would have fetched from a local well or other source), a bucket, and cloths for wiping the dirt floor. Above the girls, on the chalkboard are the words, "Room Sweepers." Girls have onerous, gender-specific domestic duties at home, and these duties, as well as the girls' identities as doers of these duties are very often reinforced at school. Figure 10 contrasts girls and boys' noninstructional time at school. 
In this drawing, three girls are transporting water to the school, while boys are playing football in the school grounds. The longer description provided on a separate piece of paper reads:

The girls are kept busy fetching water while the boys are playing. This denies the opportunity for the girls to play. This work as well could be done by the boys, i.e., fetching water. Girls are overworked, kept busy, boys free.

Most family homes, and even many schools, do not have running water, and so water must

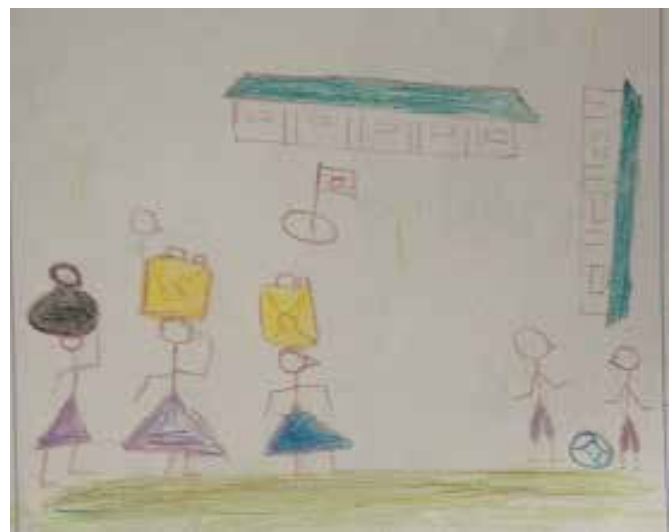

Figure 10. Girls transporting water;

Boys playing football be fetched from a nearby stream, river, well, or other source. This is typically done by girls and women. Yellow jerry cans and large gourds represent the collection of water, which is very demanding labour, often involving multiple trips per day over long distances. The loads are heavy, and the paths can be steep, rocky, and/or unsafe, and the journey exhausting, especially in the mid-day heat without sufficient nourishment. The surface level contrast between work and play is stark, and the freedom differential between girls and boys is apparent. However, deeper analysis and extrapolation based on contextual familiarity speaks to expectations of girls' servitude and unpaid labour, as well as the harsh physical demands (hard labour often without sufficient nourishment or rest) that impact not only their bodies but their overall wellbeing and capability to learn to their full potential.

These drawings prompted participants to discuss not only the unfair burden of work for girls, but also the time cost; the many hours of domestic labour severely constrained the time left for studying. In their reflective pieces, participants made the following comments: “...boy and girl both should be given time to do their homeworks at home"; "...made men realize there should be no [unequal] division of labour"; "the roles should be divided [equally] for the children [girls and boys]".

\section{Participants' observations on drawings}

Interestingly, the female and male participants alike all agreed that each of the inequalities depicted in these drawings existed and were even commonplace. I had anticipated that perhaps the male participants might be unaware of particular forms of abuse or discrimination against girls, or might suggest that injustices perpetrated against girls were not as serious or prevalent as the female participants believed them to be, but this was not the case. The male participants, generally, were as passionate as the female participants about the urgent importance of bringing about change to protect and support girls so that they were able to fully and equally participate in education. 


\section{Drawing as a Mode to Imagine Gender Equality}

The participants were then asked to create drawings representing gender equality and girls' empowerment. Drawing imagined future identities and communities has the potential to concretize and more full develop ideas because "one has to actually draw a world into existence" (Literat, 2013, p. 88). Below are some of the drawings of imagined gender equality.

\section{Disruption of traditional roles and responsibilities}

Many of the drawings depict girls and women assuming roles typically performed by boys and men, and vice versa. Figures 16 to 21 show boys and men performing tasks typically undertaken by girls and women. In each of these drawings, the objects (pots, baskets, jerry cans, homes, clothes, crops, landscape, brooms, etc.) featured were all familiar to all participants and representative of the context of rural North West Uganda, as were the actions associated with them.

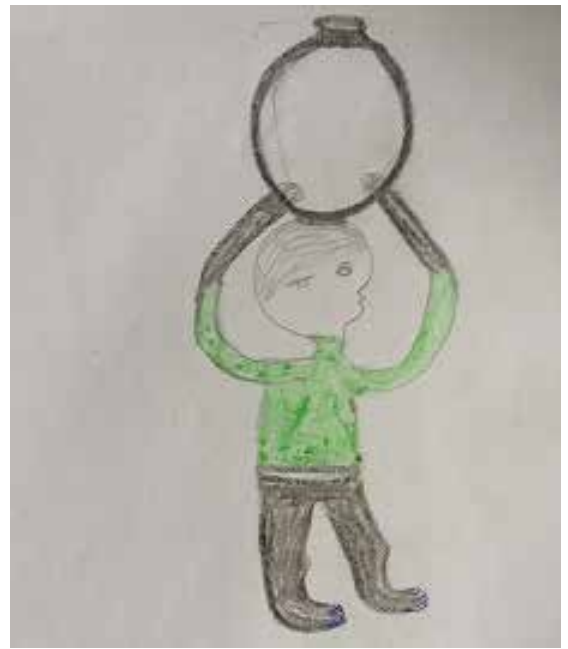

Figure 11. Boy carrying water

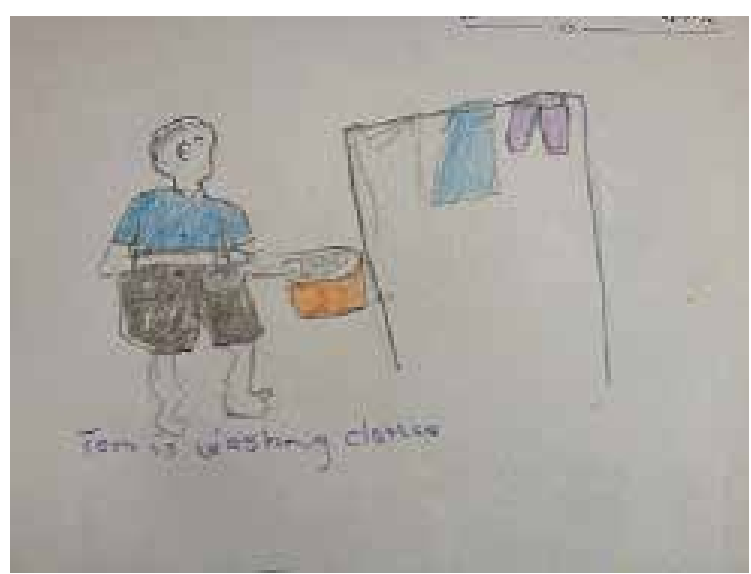

Figure 12. Boy washing clothes

There are no washing machines in areas with no electricity and so girls and women must wash all clothes by hand, using scarce water resources. This is a daily activity that requires a significant amount of time. In this drawing, the boy is washing the clothes.

Girls and women are responsible for washing dishes ('utensils') several times a day. In this drawing, a boy is doing that task.

Typically, households do not have access to electricity and/or do not possess gas or propane-based stoves, so all of the cooking is done using firewood. Firewood is collected by girls and women everyday from the surrounding area and transported back to the home. This is a time- and labour-intensive task. It can also be a dangerous undertaking due to vulnerability to many environmental factors, such as poisonous snakes, wild animals, challenging terrain, as well as assault by men. Girls and women typically prepare all meals. 


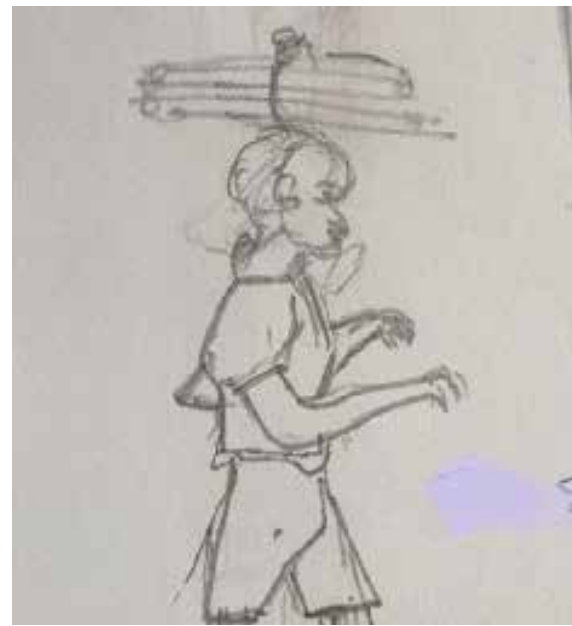

Figure 14. Boy carrying firewood

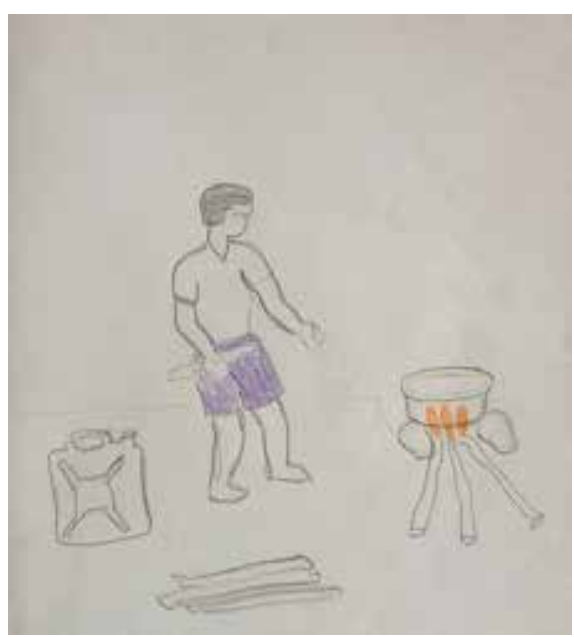

Figure 15. Boy cooking

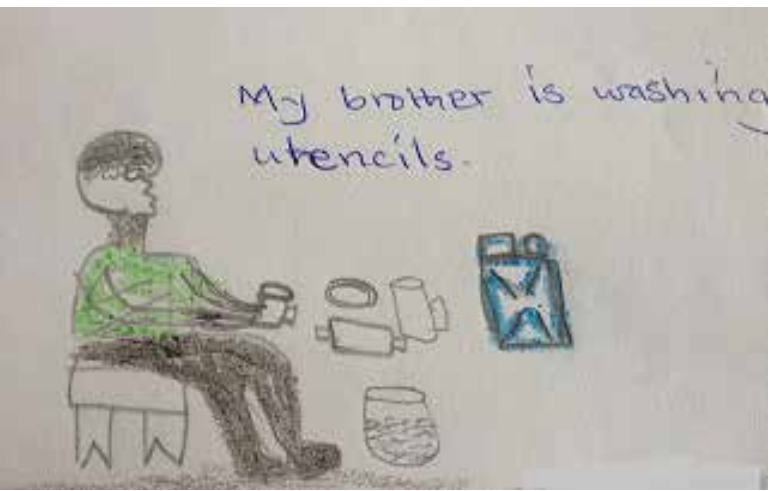

Figure 13. Boy washing dishes

At a surface level, these drawings depict boys and men doing the tasks normally assigned to girls and women. However, in the shared context of the participants, who were intimately familiar and experienced with these tasks, a deeper and more complex meaning was represented. For example, all the participants understood the intense effort, enormous amount of time, and drudgery involved in transporting water in jerry cans over long distances several times a day. Even though this is the task of girls and women, most boys and men have had to do this at some point in their lives and so they appreciate how difficult it is. Almost all the tasks are focused on the home, domestic work and caring for others, or very specific movement to and from a designated destination (water source, market). Thus, the visual representations of the objects, as well as the subjects' interactions with then, offers a sensory immediacy and imprinting that reaches beyond words.

Drawings also represented girls and women undertaking roles and activities generally only available to boys and men, as indicated in Figures 16 to 18. 


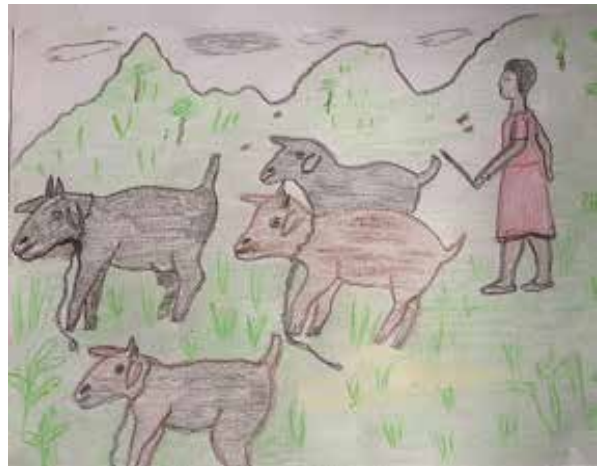

Figure 16. Girl grazing goat

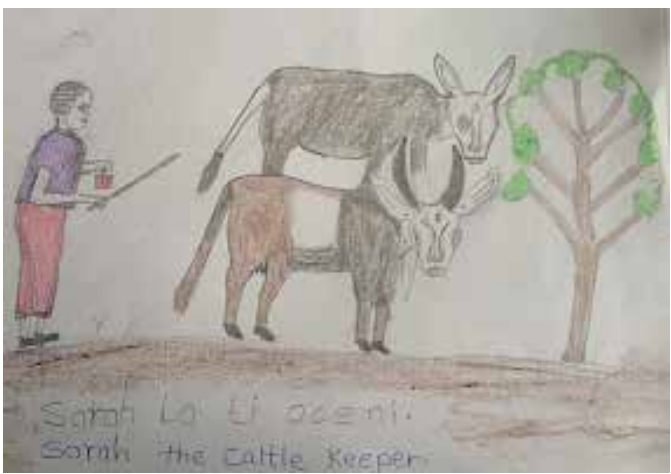

Figure 17. Female cattle-keeper

Many families have some kind of livestock, and it is typically the boys' responsibility to feed and care for the animals. One of the striking aspects of Figure 17 is that the girl is wearing trousers. This is almost never seen, and in this context makes a radical break with gender norms.

Skilled, paid labour positions, such as that of a carpenter, are almost exclusively occupied by men.

These drawings of girls and women performing work usually considered the domain of boys and men again communicate meaning beyond the surface level of the images. Aspects of

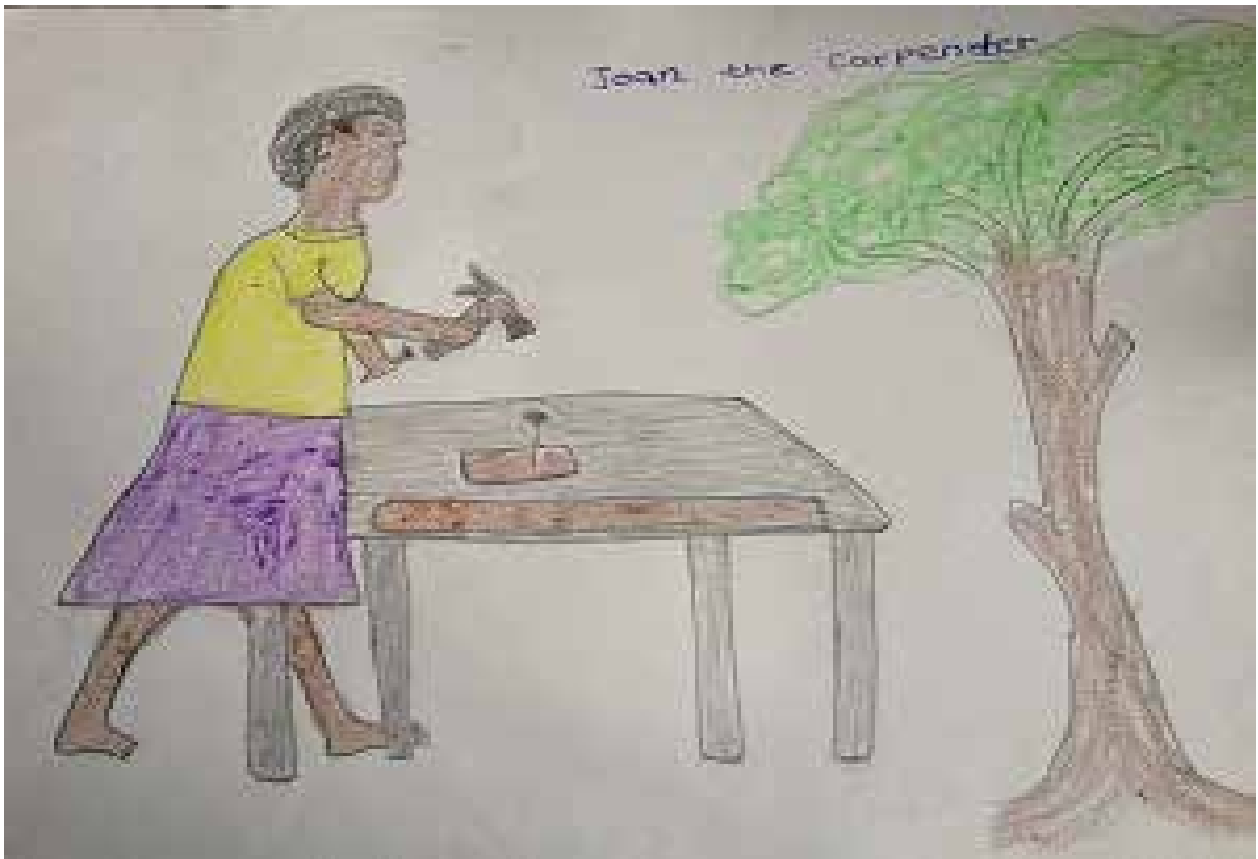

Figure 18. Female carpenter 
freedom, value, and power are associated with these visual productions. For example, grazing animals affords a certain freedom of movement that is available to boys and men, but not to girls and women. And, more highly paid vocations, such as carpentry, are generally the domain of men. The ability to earn an income and the associated authority to determine how this money is spent affords the earner a great deal of power. Typically, the men in the family earn the most money and thus wield the most power. Portraying a woman in this position has important implications for her empowerment.

Reflections related to the themes expressed in these drawings include: "...girls can also do activities done by the boys... and boys can cook, fetch water, etc"; “... a boy should be able to cook at home.... girl should be able to graze animals"; [there are] gender related problems both at schools and in our communities [that] we need to solve"; "Not only men can undertake hard tasks but also women."

\section{Imagining possibilities through drawing}

Imagining gender equality through the mode of drawing also inspired some participants to consider contexts and opportunities beyond the local and familiar.

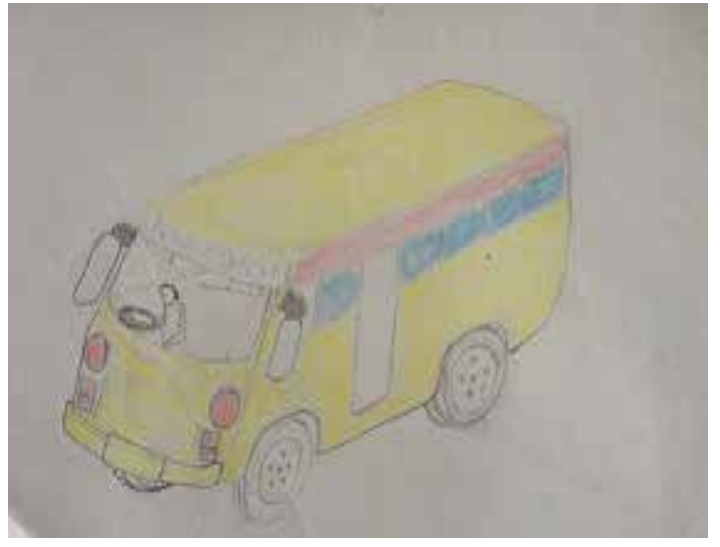

Figure 19. Female bus driver

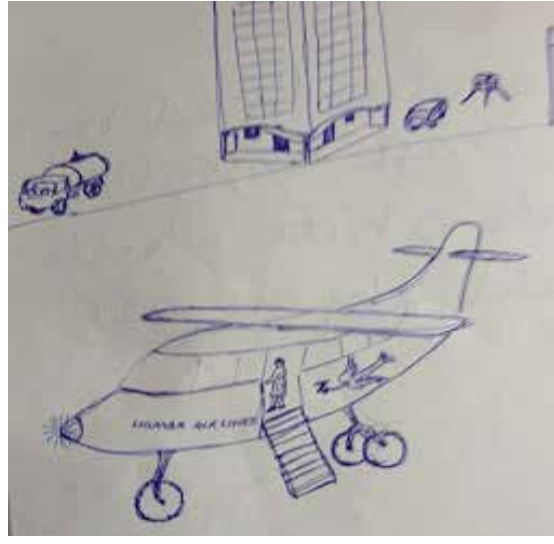

Figure 20. Female pilot

Local transportation around villages and towns consists primarily of boda-bodas (small motorbikes, operated almost exclusively by men, that are often hired out), bicycles (although women and girls are not permitted to ride bicycles), cars/taxis (mostly driven by men), and matatus (passenger vans driven by men). Buses are used to travel longer distances and are almost always operated by men.

Figure 20 depicts a female pilot. Although all the participants had seen planes flying in and out of the local airport, planes as means of transportation was beyond their financial capacity. But, planes transported politicians, dignitaries, and professionals who visited their towns and villages. Almost all, if not all, pilots who operated these planes were men.

These two drawings offer glimpses of jobs and careers that women could have if they had the opportunity to pursue them. The women in these drawings are portrayed as perfectly 
capable of executing the skills required for these jobs, as well as succeeding in the math and science-based programs required to gain the necessary qualifications. Thus, the underlying message to the prompt "imagine what gender equality looks like" is that if there were not obstacles that prevented them from girls and women from working towards and taking up these kinds of careers, they would be capable of doing so. And, these obstacles are a subtext of the drawings, at least for the participants. In very poor rural areas of Uganda, such as the area in which this study took place, the multitude and complex challenges related to education result in very few students completing secondary school and continuing on to post-secondary education. And, in areas of extreme poverty, girls face even greater obstacles than normal to accessing education; therefore, the few students who might achieve a post-secondary education would primary be male.

One female teacher noted in her reflection: “... [as] female teachers, we are supposed to guide, counsel, care, advise, whenever they [girls] are in problems...so that they aim high become somebody."

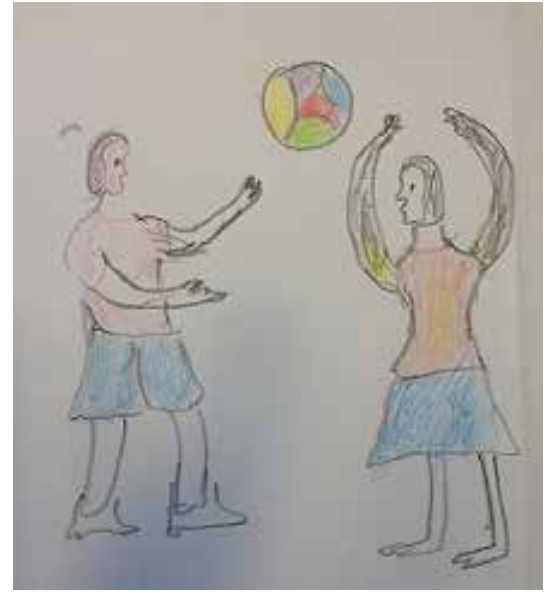

Figure 21. Girl and boy playing netball

\section{Envisioning equality and positive gender relationships in the school context}

Finally, some drawings were created that depicted the gender equality within female/male interrelationships within the school context. Figure 21 shows a girl and boy playing netball together.

They are in the schoolground, wearing their school uniforms. Netball is considered to be the game for girls (football is the game for boys), so the semiotic significance is the dissolution of gendered binaries with respect to sports.

Figure 22 depicts students in a math class. Interestingly, there are two girls and only one boy, and one of the girls has her arm raised to presumably answer a question, or to ask for clarification. The message being conveyed in this drawing is one of inclusion, equality, and empowerment. Unlike Figure 5 where the boy is receiving resources (access to chalk, chalkboard) and attention from the teacher, and the girl stands behind him, neglected, here the girls sit beside the boy and are enabled to fully participate. Also, it is significant that this is a math class, as girls are often thought to be much less capable than boys in math and science. 


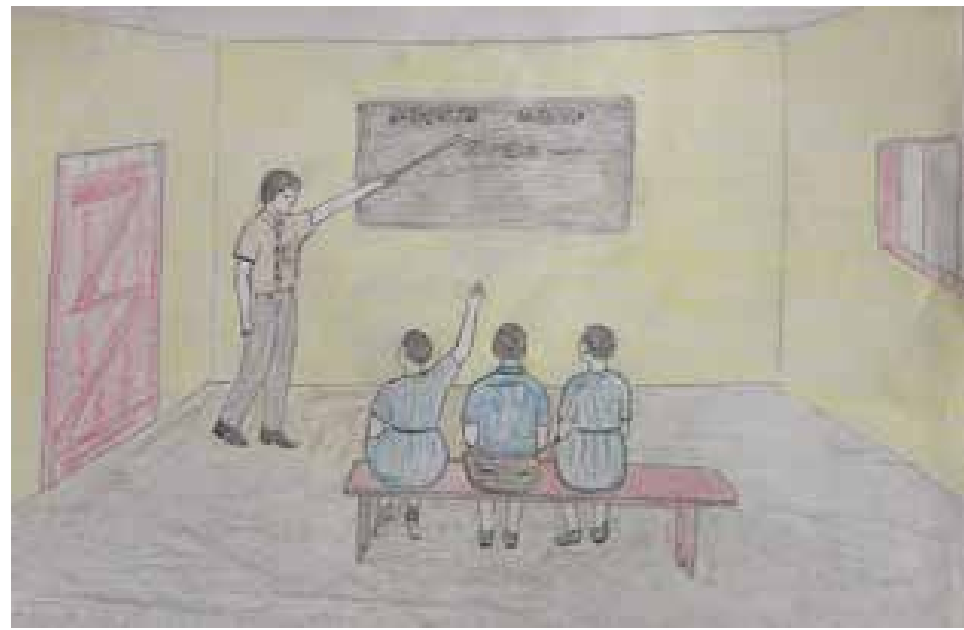

Figure 22. Students in a math class

Figure 23 features girls and boys equally sharing in responsibilities, chores, and play around the school.

The drawing at the left shows a girl and boy acting as security guards around the school; this is considered a role for male students. In the middle drawing, a girl and boy fetch water together; this is considered work for female students. And, in the drawing on the right, a girl and boy play together in the schoolground.

Figures 21-23 offer representations of imagined gender equality, and healthy, positive gender relationships. There is a strong sense of collaboration, camaraderie, and mutual respect.

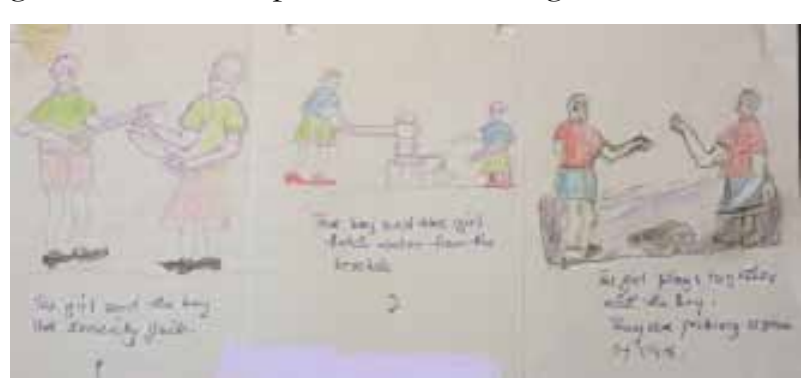

Figure 23. Girls and boys engaged in activities around school

Discussions around promoting gender equality in the classroom were animated and enthusiastic. Reflection comments included: "both boys and girls are to be considered equal especially in answering questions, playing roles, discussions, leadership, and other activities at school"; "giving equal opportunity for both girls and boys in discussion questions in class"; "women and men should have equal rights"; "girls can also do the same as boys if the chance is given to them"; "I have learned that girls/boys can do well in all the aspects... [and]should be treated equal."

\section{Multimodality as a Way to Facilitate Engaged Scholarship}

Drawing was offered as an alternative mode to language as a means by which all participantsparticularly those who were reticent to contribute to the initial discussions but whose voices 
were perhaps the most important to be included — could share their thoughts and experiences. Drawing, in this case, served as a catalyst for other modes-writing and discussions that, when integrated, enabled participants to explore issues in more complexity and encouraged contributions from all participants. Reflective comments on this process included: "women and men both should be encouraged to answer questions and contribute in meetings/seminars" (male participant); "made women to feel that they are equal to men"; "we were able to share experiences in our discussions which was so interesting"; "both male and female participants were active in the discussions and gave solutions and way forward...."

A multimodal approach to investigating the complex and sensitive topic of gender inequality sufficiently disrupted normative power dimensions and anticipated discourse patterns to create a new social dynamic in which voices (women's) that were not normally heard, or were typically sidelined, were sought out and openly valued. In the end, spoken and written modalities remained as the dominant modalities, and the modalities of cohesion, yet the forays into alternative forms of communication and representation that imbued participants with power of expression that they were unaccustomed to, were critical to democratizing these dominant modalities.

The report submitted at the end of the workshop-for review by university, donor, and government stakeholders - included all voices, through drawings as well as text. The intention was for this report to apprise the stakeholders of the realities of gender inequality in local contexts, the needs of educators with respect to implementing gender-responsive measures in their schools, as well as to inform future policies and programming. This two-way knowledge exchange, argues Boyer (1996), is essential to engaged scholarship: “...the academy must become a more vigorous partner in the search for answers to our most pressing social, civic, economic and moral problems, and must reaffirm its historic commitment to what I call the scholarship of engagement" (p. 11).

\section{Conclusion and Recommendations}

As a communicative mode, drawing enabled the participants to represent a wide range of issues related to gender inequality related to education, within the school context, but also as it extended into the community more generally. Unequal power relationships, gender(ed) divisions, exclusion and marginalization, victimization and abuse were represented in a concrete and sensory was through the mode of drawing, as were possibilities for gender equality. The inclusion and communication of important details (e.g., school uniforms, jerry cans for carrying water, benches and desks, schoolgrounds, tears falling from a girl's face, and the postures and actions of the subjects), were aspects of design and production that drawing as a mode opened up for distribution, or consideration, amongst the participants. The presence of these drawings constituted a felt experience as they inhabited the space (taped to the walls) in which we worked. The drawings were also powerful as representations of the voices of all participants. Each participant's voice had equal weight, value, and presence and thus represented an inclusive, empowering, and democratic space of co-learning. In addition, within that shared space and time of the course were also signs whose meanings

Engaged Scholar Journal: Community-Engaged Research, Teaching, and Learning 
resonated in particular ways with the participants who shared understandings of them and what they represented. For example, the participants immediately recognized school uniforms as signs that situated the children at school. Houses and schools were signs identified by their architectural features common to schools and houses in the region. Everyday objects such as machetes, jerry cans, gourds, sticks, benches, long desks, and even mango trees were significant signs embedded within the pictures, each with semiotic significance. Although someone not familiar with the context might be able to interpret or surmise much of the intended meaning, the semiotic depth and impact was intensely resonant with the participants as they were intimately familiar with the signs.

This immediate access to the signs embedded in the drawings enabled the participants to probe more deeply into questions around gender stereotypes, discrimination, and abuse. The visual representations were both points from which discussions emanated, as well as anchors to which discussions returned. The multimodal investigation included all voices and enabled participants to stay with images in ways that encouraged and supported focused and multilayered reflection on gender constructs and assumptions as well as worked in conjunction with other modes — such as written text and spoken language- to offer deeper, richer, more complex meanings representing a multimodal experience. Multimodality as a domain of inquiry served as means by which a more collaborative and supportive professional community was established and a scholarship of engagement established to share the experiences and ideas of the participants with larger educational institutions and structures. Based on this study, I have the following recommendations:

1) Involve the frontline implementers of important, socially transformative policies and initiatives - such as teachers - in consultations where they are encouraged to communicate their experiences and ideas through modes other than the formal, often intimidating spoken and written modes that represent power and authority. True partnership and engagement requires a safe space and receptivity to a wide range semiotic representations that encourage, value, and respect all voices; only policies and programming that are accessible, relevant, and respond to the needs of the implementers will have life beyond the documents.

2) Use drawing as a pedagogical method that engages children in imagining what gender equality might look like to them. This could enable children who are often excluded, or are too shy to verbally communicate their ideas to share their thoughts and feelings. This in turn, could be used as an opportunity to build a safe and inclusive community that models positive gender relationships. 


\section{About the Author}

Shelley Jones (corresponding author) is Associate Professor in the College of Interdiscplinary Studies at Royal Roads University. She is Head of the Year One and Bachelor of Interdisciplinary Studies Programs. Her research focus is gender, education, and empowerment in East African contexts. Email: shelley.12jones@royalroads.ca

\section{References}

Bantebya, G.K., Muhanguzi, F.K., \& Watson, C. (2014). Adolescent girls in the balance: Change and continuity in social norms and practices around marriage and education in Uganda. London, UK: Overseas Development Institute.

Barker, D. (2004). The scholarship of engagement: A taxonomy of five emerging practices. Journal of Higher Education Outreach and Engagement, 9(2), 123-137.

Blackden, C.M. (2004). Out of control: Gender and poverty in Uganda. A strategic country gender assessment (Discussion draft). Washington, DC: World Bank.

Bourdieu, P., \& Wacquant, J.D. (1992). An invitation to reflexive sociology. Chicago, IL: University of Chicago Press.

Boyer, E.L. (1996). The scholarship of engagement. Journal of Public Service and Outreach, 1(1), 11-20.

Butler, J. (1988). Performative acts and gender constitutions: An essay in phenomenology and feminist theory. Theatre Journal, 40(4), 519-531.

Chilisa, B., \& Ntseane, G. (2010). Resisting dominant discourses: implications of indigenous, African feminist theory and methods for gender and education research. Gender and Education, 22(6), 617-632.

Cope, B., \& Kalantzis, M. (Eds.). (2000). Multiliteracies: Literacy learning and the design of social futures. East Sussex, UK: Psychology Press.

Faughnan, P. Global Partnership for Education (2016, Oct. 13). Fighting for girls' education in Northern Uganda. Global Partnership for Education. Retrieved from http://www.globalpartnership. org/blog/fighting-girls-education-northern-uganda

Geiger, T. (2002). Female education in Sub-Sabaran Africa: Importance, obstacles and prospects. Final student paper presentation, University of Aarhus, Denmark. Retrieved from http://www.ulandslaere. au.dk/Opgavestof/2002/EndeligeOpgaver_2002/ FemaleEducationSubSaharanAfrica_ TinneGeiger.pdf

Government of Uganda (2007). Uganda Vision 2040. Kampala: JONES. Retrieved from https://www. gou.go.ug/content/uganda-vision-2040

Grbich, C. (2013). Qualitative data analysis: An introduction (2nd ed.). Thousand Oaks,CA: Sage.

Jewitt, C. (2008). Multimodality and literacy in school classrooms. Review of Research in Education, 32, 241-267.

Jones, S. K. (2008). Secondary schooling for girls in rural Uganda: Challenges, opportunities, and emerging identities (Doctoral dissertation, University of British Columbia, Vancouver, Canada). Retrieved from https://circle.ubc.ca/handle/2429/279?show=full 
Jones, S. (2011). Girls' secondary education in Uganda: Assessing policy within the Women's Empowerment Framework. Gender and Education, 23(1), 385-413.

Jones, S. (2015). Post-primary education, employment, and capabilities: Insights from young women in rural Uganda. African Education Review, 12(1), 127-141.

Kakuru, D. M. 2006. The combat for gender equality in education: Rural livelihood pathways in the context of $H I V / A I D S$. African Women Leaders in Agriculture and the Environment, AWLAE Series No. 4. Wageningen, The Netherlands: Wageningen University Press.

Kendrick, M., \& Jones, S. (2008). Girls' visual representations of literacy in a rural Ugandan community. Canadian Journal of Education, 31(2), 371-404.

Kendrick, M., Jones, S., Mutonyi, H., \& Norton, B. (2006). Multimodality and English education in Ugandan schools. English Studies in Africa, 49(1), 95-114.

Kress, G. (2011). 'Partnerships in research': Multimodality and ethnography. Qualitative Research, 11(3), 239-260.

Kress, G. \& Jewitt, C. (2003). Introduction. In C. Jewitt \& G. Kress (Eds.), Multimodal literacy (pp. 1-18). New York, NY: Peter Lang.

Kress, G., \& van Leeuwen, T. (2001). Multimodal discourse: the modes and media of contemporary communication. London, UK: Arnold.

Kwesiga, J. (2003, November). Review of the 2005 gender parity Millennium Development Goal in Uganda and proposed strategies for achieving this target. Department of Women and Gender Studies. Makerere University, Kampala, Uganda.

Lather, P. (2004). Issues of validity in openly dialogic research: Between a rock and a soft place. In Y. S. Lincoln and N. K. Denzin (Eds.), Turning points in qualitative research: Tying knots in a bandkerchief, (pp. 185-216). Walnut Creek, CA: Altamira.

Lawson, D. (2003). Gender analysis of the Ugandan National Household Surveys, 1992-2003. Draft report prepared for the revision of the Poverty Eradication Action Plan, October, 2003.

Literat, I. (2013). "A pencil for your thoughts": Participatory drawing as a visual research method with children and youth. International Journal of Qualitative Methods, 12(1), 84-98.

Maguire, P. (1996). Considering more feminist participatory research: What's congruency got to do with it?. Qualitative Inquiry, 2(1), 106-118.

Ministry of Education and Sports (MoES). (2013). National Strategy for Girls' Education (2014-2019). Kampala, Uganda: Ministry of Education and Sports (MoES) with support from UNICEF, the UN Joint Programme on Gender Equality (UNJPGE) and UK Aid.

Ministry of Education and Sports (MoES). (2016). Gender in education sector policy. Kampala, Uganda: MoES.

Ministry of Gender, Labour, and Social Development (MGLSD). (2007). The Uganda gender policy. Kampala, Uganda: MGLSD.

Mirembe, R., \& Davies, L. (2001). Is schooling a risk? Gender, power relations, and school culture in Uganda. Gender and Education, 13(4), 401-416.

Mlama, P., Dioum, M., Makoye, H. Murage, L., Wagah, M., Washika, R. (2005). Gender responsive pedagogy: A teacher's handbook. Nairobi, Kenya: Forum for African Women Educationalists.

Norton, B. (2013). Identity and language learning: Extending the conversation. (2nd Edition) Bristol, UK: Multilingual Matters.

Pink, S. (2011). Multimodality, multisenoriality and ethnographic knowing: Social semiotics and the phenomenology of perception. Qualitative Research, 11(3), 261-276. 
Rose. G. (2016). Visual methodologies: An introduction to researching with visual materials. Thousand Oaks, CA: Sage.

Roswell, J., \& Pahl, K. (2007). Sedimented identities in texts: Instances of practice. Reading Research Quarterly, 42(3), 388-404.

Stoebenau, K., Warner, A., Edmeades, J.D., Sexton, M. (2015). “Girls are like leaves on the wind”: How gender expectations impact girls' education-A closer look from West Nile, Uganda. Washington, DC: International Center for Research on Women.

Tozer, S. (2000). Class. In D.A. Gabbard (Ed.), Knowledge and power in the global economy: Politics and the rhetoric of school reform (pp. 149-159). Mahwah, NJ: Lawrence Erlbaum Associates.

Uganda Bureau of Statistics (UBOS). (2012). Education sector: Gender statistics profile. Kampala, Uganda: UBOS.

Uganda Bureau of Statistics (UBOS). (2017). Uganda national household survey 2016/17. Kampala, Uganda: UBOS.

UNDP. (2015). Uganda human development report 2015: Unlocking the development potential of Northern Uganda. Kampala, Uganda: UNDP.

United Nations Development Programme (UNDP). (n.d.) UNDP Uganda Gender Equality Strategy 2014-2017: Investing in gender equality for Uganda's socio-economic transformatio. Kampala, Uganda:UNDP Uganda. Retrieved from UNDP Uganda’s Gender Equality Strategy 2014-2017.

UNESCO Institute for Statistics. (2017). Uganda: Education and literacy. Montreal, Canada: UNESCO Institute for Statistics. 